\title{
An Elastoplastic Model Considering Sand Crushing
}

\author{
Yangping Yao ${ }^{1}$, Naidong Wang ${ }^{1}$, Haruyuki Yamamoto ${ }^{2}$, and Huilin Xing ${ }^{3}$ \\ Department of Civil Engineering, Beihang University, \\ Beijing 100083, P.R. China \\ ypyao@buaa.edu.cn, wangnd@ce.buaa.edu.cn
}

Graduate School for International Development and Cooperation, Hiroshima University,

Higashi-Hiroshima 739-8529, Japan

yamamoto@idec.hiroshima-u.ac.jp

Earth Systems Science Computational Center, University of Queensland,

St Lucia, Brisbane, QLD 4072, Australia

xing@esscc . uq . edu . au

\begin{abstract}
The behavior of sand crushing will appear when the confining pressure is up to a certain value, which results in disappearing of the positive dilatancy of sand. Adopting a new hardening parameter with the crushing stress, an elastoplastic constitutive model considering sand crushing is proposed. Comparing the conventional triaxial compression test results with the model prediction, it shows that the proposed model can reasonably describe the dilatancy of sand from positive to negative.
\end{abstract}

Keywords: Crushing, Elastoplastic model, Hardening, Sand, Dilatancy.

\section{Introduction}

Many triaxial experiments ${ }^{[1,2]}$ indicate that sand presents crushing at a high confining stress, which results in positive dilatancy at low confining stress and negative dilatancy at high confining stress. The peak strength of sand also decreases with the confining stress increasing. Therefore, it is necessary to develop an elastoplastic constitutive model to describe the mechanical behavior of sand crushing.

\section{The Model Considering Sand Crushing}

Referencing the work by Sun et al. ${ }^{[3]}$, Nakai ${ }^{[4]}$, Yao and Luo ${ }^{[5]}$, the relationship between the elastoplastic volumetric strain $\varepsilon_{v}^{p}$ (or $\varepsilon_{v}^{e}$ ) and the mean stress $p$ under isotropic consolidation condition could be assumed as Eqs.(1) and (2):

$$
\begin{gathered}
\varepsilon_{v}^{e}=C^{e}\left[\left(p / p_{\mathrm{a}}\right)^{m}-\left(p_{0} / p_{\mathrm{a}}\right)^{m}\right] \\
\varepsilon_{v}^{p}=\left(C^{e p}-C^{e}\right)\left[\left(p / p_{a}\right)^{m}-\left(p_{0} / p_{a}\right)^{m}\right]
\end{gathered}
$$


where $p_{0}$ is the initial mean stress, $p_{\mathrm{a}}$ is the atmospheric pressure, $C^{e p}$ is the compression index, $C^{e}$ is the swelling index and $m$ is a coefficient for sand. There are two examples shown as Fig.1.
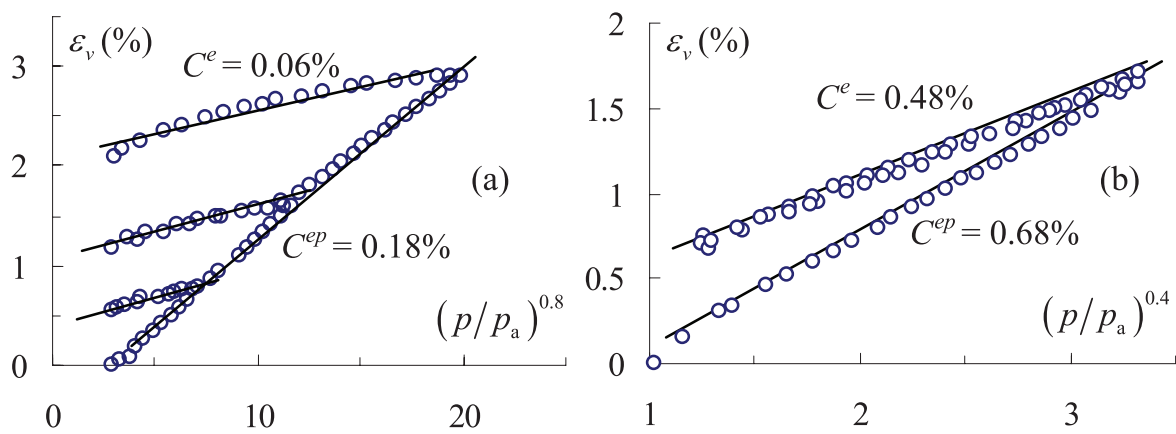

Fig. 1. The loading-unloading tests of isotropic compression, which of cement sand is shown in panel(a), Toyoura sand in panel(b)

Revising the hardening parameter ${ }^{[6,7]}$ developed by Yao et al. as

$$
\begin{array}{r}
H=\int d H=\int \Theta d \varepsilon_{v}^{p}=\int \frac{M_{p t}^{4}}{M_{f}^{4}} \frac{M_{f}^{4}-\eta^{4}}{M_{p t}^{4}-\eta^{4}} d \varepsilon_{v}^{p} \\
M_{f}=M\left(p / p_{c}\right)^{-n} \\
M_{p t}=M\left(p / p_{c}\right)^{n}
\end{array}
$$

in which $M_{p t}$ is the stress ratio at characteristic point, $M_{f}$ the stress ratio at shear failure, $M$ the stress ratio at critical state, $\eta$ the stress $\operatorname{ratio}(\eta=q / p), p_{c}$ the crushing stress, $n$ a material parameter of sand $(0<n<1)$. The parameters of proposed model are $M, p_{c}$ and $n$. In the proposed model, the equations of the yield locus and plastic potential are similar to the modified Cam-clay model's ${ }^{[8,9]}$ on the p-q plane. Adopt the revised hardening parameter $H$ with crushing stress $p_{c}$ to replace the plastic volumetric strain $\varepsilon_{v}^{p}$ in Cam-clay model. The yield function is given as

$$
\left(C^{e p}-C^{e}\right)\left(\frac{p_{0}}{p_{a}}\right)^{m}\left[\left(\frac{p}{p_{0}}+\frac{q^{2}}{M^{2} p p_{0}}\right)^{m}-1\right]-H=0
$$

The stress-dilatancy equation is expressed as

$$
d \varepsilon_{v}^{p} / d \varepsilon_{d}^{p}=\left(M_{p t}^{2}-\eta^{2}\right) / 2 \eta
$$




\section{Prediction Versus Experiments}

The following seven soil parameters used in the proposed model: $C^{e}, C^{e p}, m, M, p_{c}, n$ and the poisson coefficient $v$, all of which can be determined via TC tests. The parameters $C^{e}, C^{e p}$ and $m$ are confirmed at isotropic consolidation conditions as in Fig.1. The parameters $M, p_{c}$ and $n$ are determined by drained triaxial compression tests at different initial stresses. The model parameters for Toyoura sand are listed in Tab.1 and the value of atmospheric pressure $p_{a}$ is given as $0.1 \mathrm{MPa}$.

Table 1. There are seven parameters required for the proposed model

\begin{tabular}{|c|c|c|}
\hline Isotropic consolidation & $\begin{array}{c}\text { Triaxial } \\
\text { compression }\end{array}$ & Elastic poisson \\
\hline$C^{e}=0.0046$ & $M=1.35$ & $v=0.3$ \\
$C^{e p}=0.0068$ & $p_{c}=5.9 \mathrm{MPa}$ & \\
$m=0.4$ & $n=0.103$ & \\
\hline
\end{tabular}

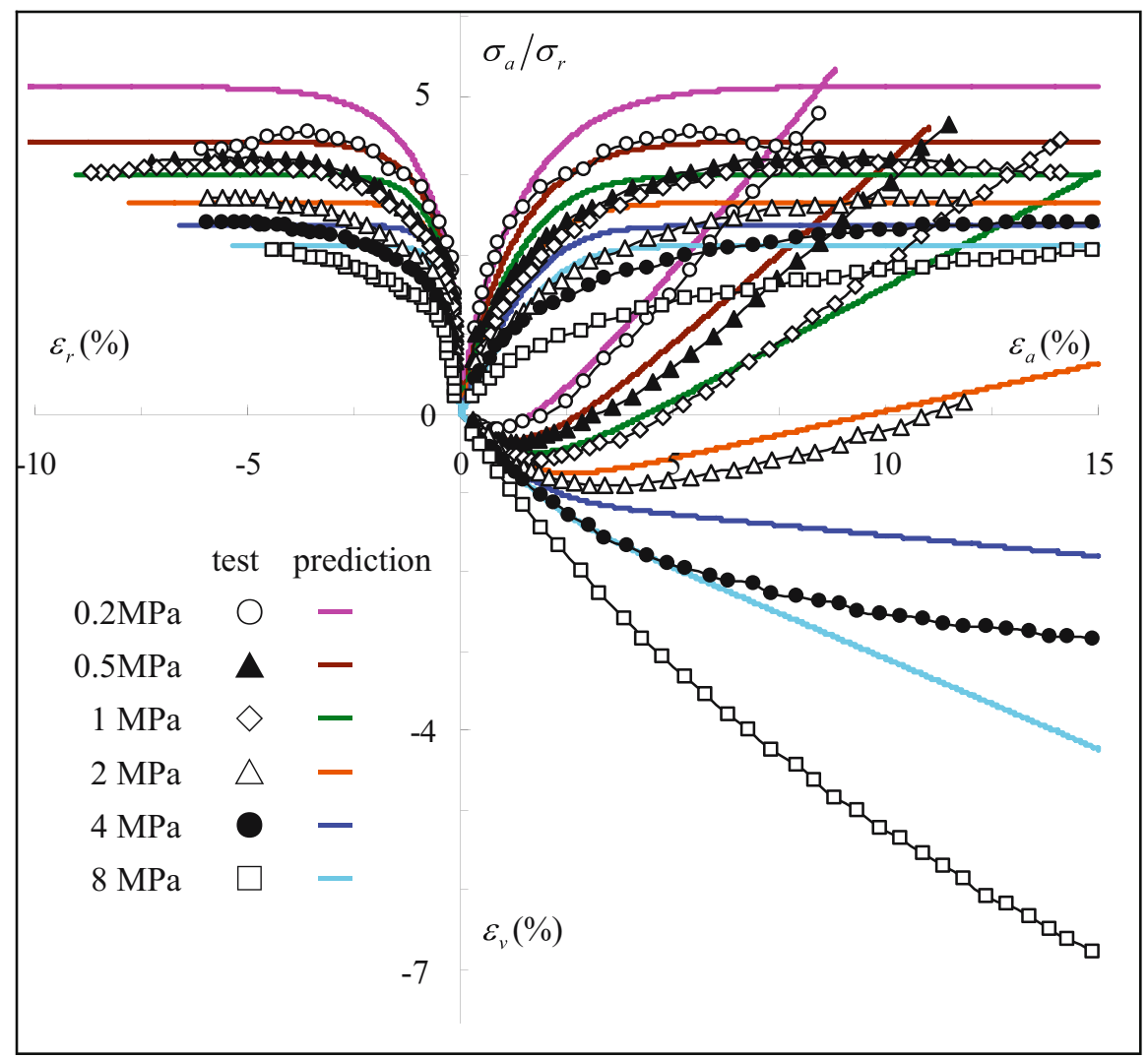

Fig. 2. The test results (data after Sun et al. ${ }^{[10]}$ ) and the predicted stress-stain curves by proposed models in this paper 
The test results and the predicted relationships between axial strain $\varepsilon_{a}$, radial strain $\varepsilon_{r}$, volumetric strain $\varepsilon_{v}$ and principal stress radio $\sigma_{a} / \sigma_{r}$ are shown in Fig.2.

Analyzing the prediction results as shown in Fig.2, it can be seen that: (1) The predicted curves by the proposed model agree well with the test results for Toyoura sand under conventional triaxial compression conditions except the $\varepsilon_{a}-\varepsilon_{v}$ curves at $p=4$, $8 \mathrm{MPa}$. (2) When the confining stress of sand rises, the strength (peak principal stress ratio) decreases. (3) When the confining stress of sand rises, the volumetric dilatant degree of sand decreases.

\section{Conclusions}

(1)Because of the behavior of sand crushing, the peak principal stress ratio and the degree of positive dilatancy for conventional triaxial compression tests both decrease when the confining stress rises. The dilatancy will disappear when the confining stress is larger than the crushing stress.

(2)The proposed elastoplastic constitutive model, adopting the new hardening parameter revised by the crushing stress, can reasonably describe the stress-strain behavior and the dilatancy of sand.

\section{Acknowledgements}

This paper is supported by the National Natural Science Foundation of China, NSFC (No.10672010 \& No.50479001).

\section{References}

1. Daouadji, A., Hicher, P.Y., Rahma, A.: An elastoplastic model for granular materials taking into account grain breakage, Eur.J. Mech. A/Solids 20(2001)113-137

2. Fukumoto, T.: Particle breakage characteristics of granular soils, Soils and Foundations, 1992,32(1):26-40

3. Sun, D.A., Matsuoka, H., Yao, Y.P., Ichimura, M.: A transformed stress based on extended SMP criterion and its application to elastoplastic model for geomaterials, Proc. of JSCE, 2001, No.680/III-55: 211-224 (in Japanese)

4. Nakai, T.: An isotropic hardening elastoplastic model considering the stress path dependency in three-dimensional stresses, Soil and Foundations, 1989, 29(1):119-139

5. Yao, Y.P., Luo, T.: New transformed stress space and its application, Proc. of 7th Numerical Calculation and Analysis on Geomechanics, Dalian: Dalian University of Technology Press, 2001, 16-22(in Chinese)

6. Matsuoka, H., Yao, Y.P., Sun, D.A.: The Cam-clay models revised by the SMP criterion, Soils and Foundations, 1999,39(1):81-95

7. Yao, Y.P., Luo, T., Sun, D.A., Matsuoka, H.: A simple 3-D constitutive model for both clay and sand, Chinese Journal of Geotechnical Engineering, 2002, 24(2):240-246

8. Roscoe, K.H., Burland, J.B.: On the generalized stress-strain behavior of 'wet' clay. Heyman J, Leckie F A. Engineering Plasticity. Cambrige: Cambrige University Press, 1968. 535-609 
9. Wroth, C.P., Houlsby, G.T.: Soil mechanics-property characterization and analysis procedures. Proceedings of the $11^{\text {th }}$ International Conference on Soil Mechanics and Foundations Engineering, San Francisco, 1985. 1:1-55

10. Sun, D.A., Huang, W.X., Sheng, D.C., Yamamoto, H.: An elastoplastic model for granular materials exhibiting particle crushing, Key Engineering Materials, 2007, Vol.341, $1273-1278$ 